\title{
El espacio participativo y la espectaduría en el museo. Una problemática y una respuesta sobre el uso del espacio expositivo actual.
}

\section{Participatory Space and the Spectatorship in the Museum. A Problem and an Answer About the Use of today's Exhibition Space.}

Artículo recibido el 9 de junio de 20I9; devuelto para revisión el 6 de noviembre de 20I9; aceptado el I8 de noviembre de 20I9; http://dx.doi.org/IO.2220I/iie.I8703062e.2020.II6.27I4

Ioannis Mouratidis Universidad Nacional de Educación a Distancia (UNED), España, ioamouratidis@barcelona.uned.es; http://orcid.org/oooo-oooI-9294-3978

Líneas de investigación Arte moderno; arte contemporáneo; museología; gestión de museos y exposiciones.

Research lines Modern art; contemporary art; museology; museums and exhibition management.

Publicación más relevante "Documenta: Un ejemplo de ampliación del espacio expositivo para la creación de relaciones estéticas en el museo de la era digital”, en Carlos Foradada Baldellou y Pilar Irala-Hortal, coords. Re_visiones sobre arte, patrimonio y tecnología en la era digital (Zaragoza: IAACC Pablo Serrano, 2019), 365-375 (http://www.inac.es/enffiader/userfiles/files/2019/libro-arte-patrimonio-y-tecnología-en-la-era-dijital. pdf (Zaragoza: Observatorio Aragonés de Arte en la Esfera PúblicaOAAEP, Universidad de Zaragoza, noviembre, 20I8).

Resumen El espacio no es un simple escenario donde se depositan cosas y hechos sino una entidad autónoma construida socialmente. El arte actual crea espacios donde desarrollarse, con el objetivo de fomentar el surgimiento de relaciones en ellos. El presente artículo parte de esa idea de reconsideración del espacio artístico y su importancia en el desarrollo de relaciones estéticas y sociales para ver cómo el museo puede aplicarla en la renovación de su espacio expositivo. Al tener presentes las perspectivas teóricas sobre la construcción social del espacio y relacionando la construcción espacial de ciertas experiencias artísticas participativas de principios del siglo xx con algunas realizaciones presentadas en la última edición de documenta, se propone investigar las articulaciones espaciales de esas experiencias con su forma de exposición. El tema de 
este artículo es cómo pasar de un espacio museístico representacional, construido de forma historicista, lineal, nacionalista y exclusiva, a un espacio expositivo participativo de autoría compartida que represente una ciudadanía cambiante.

Palabras clave Museos; colonialismo; espacio expositivo; arte participativo; relaciones estéticas; EMST; documenta.

Abstract Space is not just a place where things and acts are deposited but an autonomous socially constructed entity. Art creates spaces where it develops with the determination to foment the emergence of relationships in them. This paper is based on the idea of a reconsidered artistic space and its importance in the development of aesthetic and social relationships to see how the museum can apply this idea in the renovation of its exhibition space. Keeping in mind the theoretical perspectives on the social construction of space and relating the spatial construction of certain participatory artistic experiences of the early twentieth century with some realizations presented in the last edition of documenta, the spatial articulations of these experiences with their form of exposition is researched. How to move from a museum representational space that is built on a historicist, linear, nationalist and exclusive way, to a participatory exhibition space of a shared authorship that represents a changing society, is the central issue.

Keywords Museum; colonialism; exhibition space; participatory art; relational aesthetics; EMST; documenta. 
DOI: https://doi.org/10.22201/iie.18703062e.2020.116.2714

IOANNIS MOURATIDIS

UNIVERSIDAD NACIONAL DE EDUCACIÓN A DISTANCIA, ESPAÑA

\section{El espacio participativo y la espectaduría en el museo Una problemática y una respuesta sobre el uso del espacio expositivo actual}

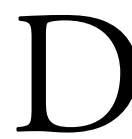
urante el siglo xIx y gran parte del xx se formó el espacio representacional del museo contemporáneo sostenido por la Historia e Historia del Arte como ciencias que crearon un modelo de exposición historicista con el principal objetivo de crear una conciencia del Estado-Nación, incluyendo en este concepto de nación a todas las distintas realidades culturales con el objetivo básico de silenciarlas. Se organizó, así, un público occidental entre un "nosotros", como heredero legítimo del progreso, y un "otro" entendido como el "primitivo" colonizado. ${ }^{\mathrm{I}}$

El pensamiento poscolonialista que surge con fuerza durante el último tercio del siglo xx de la pluma de teóricos como Edward Said, Homi Bhabha, Walter D. Mignolo y otros, y su posterior aceptación por parte de la comunidad académica occidental, pone las bases para una revisión de la Historia e Histo-

I. El sociólogo inglés Tony Bennett hace una interesante reflexión al respecto en su texto "The Exhibitionary Complex" cuya primera versión se encuentra en su libro, Tony Bennett, The Birth of the Museum: History, Theory, Politics (Londres/Nueva York: Routledge, 1995), 59-88. Parte de esta reflexión la reproduce en el catálogo oficial de d I4, Reader, en su texto: "To

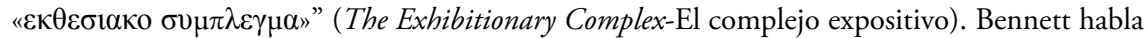
del papel de los museos ingleses y de la Gran Exposición de Londres de I85I en la construcción de ese orden social colonial por medio del ordenamiento de lo expuesto y de las reglas de uso en sus espacios expositivos y cómo este paradigma expositivo poco a poco iba encontrando seguidores en los demás países europeos y en Estados Unidos, hasta convertirse en canónico. 
ria del Arte girando el foco de investigación hacia el discurso social y estético de las pequeñas historias locales. Como postura crítica, el poscolonialismo trata la literatura producida en países que fueron o son aún colonias de otros países. Analiza los efectos del conocimiento producido en los países colonizadores sobre los países colonizados, o sus habitantes y el papel del arte en la construcción de la imagen de lo que se entiende como "el otro". La teoría poscolonial formó parte de las herramientas críticas de los años ochenta, y trata muchos aspectos de las sociedades que han sufrido el colonialismo. Se interesa, entre otros, en los modos en que el conocimiento de los países colonizadores ha colaborado en elaborar una determinada imagen del colonizado: la del ser inferior. ${ }^{2}$ La museografía contemporánea se interesa, aunque todavía no decididamente, en dicha revisión y últimamente se perfila un cambio en sus prácticas expositivas, experimentando, entre otros aspectos, con aquella organización espacial historicista.

Geógrafos y sociólogos como Henri Lefebvre, ${ }^{3}$ David Harvey ${ }^{4}$ o Doreen Massey, ${ }^{5}$ habían reflexionado acerca de la construcción social del espacio y rápidamente historiadores de arte y artistas ampliaron aquellas teorías, investigando su aplicación en el ámbito artístico. Son interesantes al respecto los trabajos

2. Entre las obras que han servido aquí como referencia se encuentran: Edward Said, $E l$ orientalismo, trad. María Luisa Fuentes (Barcelona: DeBolsillo, 2010); Walter D. Mignolo, Historias locales / diseños globales. Colonialidad, conocimientos subalternos y pensamiento fronterizo, trad. Juanmari Madariaga y Cristina Vega Solís (Madrid: Akal, 2003); y Homi Bhabha, El lugar de la cultura, trad. César Aira (Buenos Aires: Manantial, 20II).

3. Filósofo y sociólogo francés (I9OI-I99I). Entre sus líneas de investigación, interesa aquí la de la producción espacial. En su libro, Henri Lefebvre (La producción del espacio, trad. Emilio Martínez [Madrid: Capitán Swing, 2013]) entiende el espacio como una construcción política resultado de la lucha entre poderes y busca fórmulas de reconciliación del espacio mental de la filosofía con el real de la sociedad. Para lograrlo recurre muchas veces, entre otros factores, al arte.

4. Geógrafo inglés nacido en 1935 de tendencia marxista y entre los más citados actualmente. De clara influencia lefebvriana, concibe el espacio como una construcción relacional y así lo investiga en sus obras. En su interesante libro -David Harvey, Spaces of Capital. Towards a Critical Geography (Londres/Nueva York: Routledge, 2002) (Espacios del capital: hacia una geografía crítica, traducción del autor)—, se recogen artículos de las últimas tres décadas sobre la producción capitalista del espacio, entre otros temas.

5. Socióloga y geógrafa británica (1944-2016). Desde una lectura postestructuralista de Lefebvre, reflexiona sobre la espacialidad como producto de la intersección de relaciones sociales. Establece una diferencia entre lugar y espacio entendiendo que en el primero se puede desarrollar una multiplicidad de identidades. Véase Doreen Massey, Space, Place and Gender (Cambridge: Polity Press, 1994); For Space (Londres: Sage, 2005). 
de Nicolas Bourriaud, ${ }^{6}$ Claire Bishop ${ }^{7}$ o Pablo Helguera ${ }^{8}$ sobre la calidad perfomativa del espacio artístico, las relaciones estéticas que se generan en él y el arte que puede surgir de ellas. La museología actual mira con interés esas investigaciones y busca fórmulas para aplicarlas en la práctica museográfica con el objetivo de crear un nuevo espacio expositivo inclusivo.

Si reconociésemos que el espacio expositivo no es un escenario donde se depositan cosas y hechos sino una entidad autónoma construida socialmente, tal y como Lefebvre dice y si aceptásemos que el arte actual tiene como objetivo crear espectadores socialmente comprometidos en torno de un nuevo valor estético que es la relación social, según sostiene Pablo Helguera, entonces el espacio en el que se desarrolla dicho arte debería jugar un papel primordial, y la responsabilidad del museo en su creación es básica.

El presente artículo parte de esa idea de ampliación del espacio expositivo para ver cómo la institución museística actual puede aplicarla en el intento de creación de una ciudadanía participativa. Al tener como base las perspectivas teóricas sobre la construcción del espacio y las articulaciones teóricas y prácticas entre construcción del espacio y arte, se propone investigar las articulaciones entre arte espacial y formas de exposición de este arte.

El objetivo es investigar cómo el museo actual puede adecuar su relato expositivo para ser reflejo de una sociedad cambiante y agente en la trasformación del orden social mediante la transformación del orden estético que puede proponer y que la sociedad reclama. Cómo puede definir el lugar que ocupa su

6. Historiador y crítico de arte, comisario de exposiciones, nacido en Francia en 1965. Creador del término "arte relacional" que hace referencia a una corriente artística que empieza a estudiarse en los años noventa. Bourriaud acuña el término en su libro Estética relacional (Nicolas Bourriaud, Esthétique relationnelle [Dijón: Presses du Réel, 1998]) para referirse a la tendencia que da mayor importancia a las relaciones que nacen entre los distintos agentes del arte que a cualquier objeto u obra artística propiamente dicha.

7. Historiadora de arte inglesa, nacida en 1971. En su ensayo "Antagonismo y estética relacional" (Claire Bishop, "Antagonism and Relational Aesthetics," October, núm. IIo [2004]: 5I-79) revisa los presupuestos de Nicolas Bourriaud, analiza los vínculos que promueve la forma relacional y busca las posibilidades de plantear una instancia real de antagonismo.

8. Artista, teórico y comisario de exposiciones, nacido en México en 1971. Director de Programas Académicos para Adultos del мома de Nueva York En su libro Educación para un arte socialmente comprometido. Manual de materiales y técnicas (Pablo Helguera, Education for Socially Engaged Art. A Materials and Techniques Handbook [Nueva York: Jorge Pinto Books, 20II]) investiga la práctica social del arte contemporáneo, entendiéndola como su lado débil y busca fórmulas para pensar la complejidad de las prácticas artísticas desde su compromiso social. 
usuario en el espacio social por medio del lugar que le ofrece en un espacio expositivo abierto e inclusivo.

Metodológicamente, en este artículo se revisa la realización de unas propuestas artísticas concretas presentadas en documenta I4 (en adelante D I4) ${ }^{9}$ desde el punto de vista espacial. De esta manera, como objetivo aquí propuesto, se retoman elementos específicos de dichas obras relacionándose su práctica con algunas propuestas artísticas del siglo xx, como, por ejemplo, las conocidas como "excursiones" del Dadá parisino de los años veinte o las obras de John Latham del movimiento APG (Artists Placement Group) ${ }^{\mathrm{IO}}$ que utiliza libros como material escultórico, para reflexionar sobre la construcción espacial de la exposición. No se propone una revisión historiográfica o cualitativa de dicha exposición sino que se investiga la posibilidad de creación de un espacio expositivo abierto e inclusivo, sujeto a ser aplicado por parte del museo de forma más generalizada.

El trabajo se estructura de la siguiente manera: después de una breve historia de documenta, revisada aquí desde su evolución espacial a lo largo de los casi 65 años de su existencia y los cambios que experimentó y, a la vez, supuso para la ciudad de Kassel y sus habitantes, se desarrolla un comentario estético de unas propuestas artísticas de su última edición, la I4, como ejemplos de creación y uso de un espacio expositivo distinto al tradicional y se reflexiona acerca de una propuesta museográfica del recién restaurado e inaugurado museo de arte contemporáneo de Atenas, una de las sedes de D I4 en la capital griega. A continuación se aplican las observaciones anteriores en unas reflexiones acerca del espacio expositivo como espacio de representación social para

9. La decimocuarta edición de la conocida Exposición Internacional de Arte Contemporáneo tuvo lugar entre el 8 de abril de 2017 y el I7 de septiembre de 20I7. Por primera vez en su historia se llevó a cabo en dos sedes de forma casi simultánea. Salió de su sede tradicional (Kassel, Alemania) y ofreció una propuesta expositiva desde la ciudad de Atenas en Grecia. Durante un mes, entre mediados de junio hasta mediados de julio de ese año, documenta operó desde las dos sedes y sus artistas trabajaron en ambos lugares con la intención de crear con su director artístico, Adam Szymczyk, una exposición ampliada e inclusiva.

Io. El Artits Placement Group (Grupo de Colocación de Artistas) fundado por John Latham y Barbara Steveni en el Reino Unido durante la década de los sesenta y que duró hasta finales de los ochenta, fue una organización que, como nos informa Claire Bishop en su libro: Infiernos artificiales: arte participativo y politicas de espectaduría, trad. Israel Galina Vaca (Guadalajara, México: T-e-eoria, 20I6), tenía como premisa la idea de que el arte debería hacer una contribución útil al mundo y que los artistas pueden servir a la sociedad mediante sus interacciones en el contexto de las instituciones y las organizaciones tanto privadas como públicas. 
a)

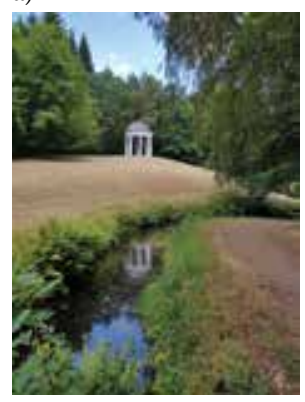

b)

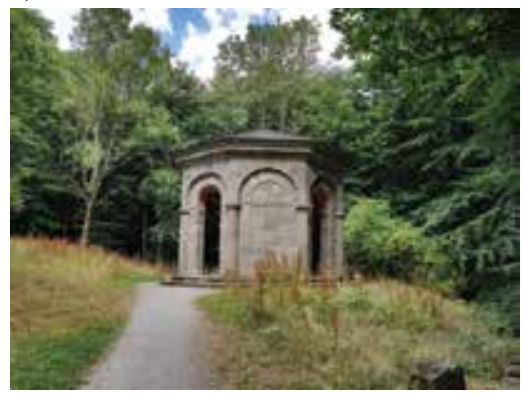

c)

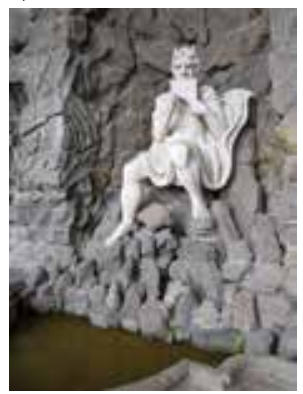

d)
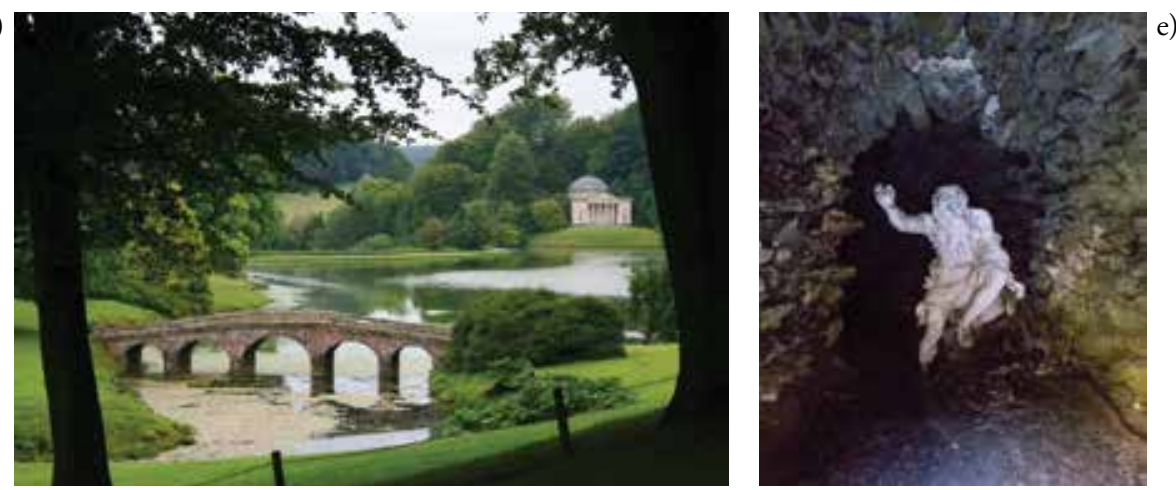

I. Superior: parque Wilhelmshöhe, Kassel, Alemania, julio de 20I8. Foto del autor. Inferior: Stourhead Gardens, Wiltshire, Inglaterra. Tomadas de https:/www.nationaltrust.org.uk/ stourhead, consultadas el I de noviembre de 2018 .

finalmente, teniendo siempre presentes las referencias teóricas, llegar a unas conclusiones de síntesis acerca de la problemática espacial en el museo actual y la necesidad de cambio de su papel hacia una institución que represente a su sociedad de la forma más inclusiva posible.

\section{Breve historia de una transformación}

La ciudad alemana de Kassel antes de la segunda guerra mundial era una ciudad profundamente romántica. Residencia del landgrave y, desde I803 príncipe elector de Hesse, se llegó a esa aproximación después de la transformación de la montaña de Wilhelmshöhe en un conjunto de jardines paisajistas de influencia inglesa (figs. ra, b, c y d). 
Entiendo aquí el término "romántico" como sensibilidad psicológica de un alma atormentada, destinada a lo que Rafael Argullol llama "La atracción del abismo". Se trata de una sensibilidad condicionada por la desgarradora sublimidad de la Naturaleza como fuerza generadora incapaz de combatirse por la pequeñez del ser humano. Un ser humano que sufre por la autoconciencia de la escisión entre él y la fuerza natural. No se trata de la Naturaleza pastoril, bucólica e idealizada de la pintura paisajista de Poussin dentro de la que el hombre vive en armonía con su entorno, sino de la Naturaleza como fuerza sublime y amenazante, tal y como la representa Caspar David Friedrich en su obra Caminante sobre el mar de nubes en la que el hombre se encuentra solo y rendido ante la fuerza sublime de una Naturaleza desconocida e intangible. Hablamos de un romanticismo como reflejo de un escenario de confrontación entre Naturaleza y hombre en el que: "se advierte la dramática nostalgia que le invade al constatar su ostracismo con respecto a ella", "I a la vez que su ansia de reconciliación con la Naturaleza que la entiende como un abismo deseado e inalcanzable, un abismo que "le provoca terror, pero, al mismo tiempo, una ineludible atracción". ${ }^{2}$

La actitud anglófila del landgrave Federico II (I720-1785) y de su hijo Guillermo IX (I743-182I) marcó el camino de aquella transformación. Federico II, enormemente interesado por el arte, siguió un plan ideado hacia casi medio siglo, por el landgrave Carlos (I645-I730), que incluía un "palacio de Hércules", una "gruta de Platón", unas cascadas desde la "cima del Olimpo" hasta la "gruta subterránea de Hades" y un sinfín de elementos paisajistas románticos de pronunciada influencia inglesa que transformarían la montaña de Wilhelmshöhe, pero que no pudieron llevarse a cabo todos en aquella época, por motivos económicos. ${ }^{13}$

Federico, que se había casado con la hija del rey Jorge I de Inglaterra, aunque mantenía una corte al ejemplo de Luis XIV y pretendía hacer de Kassel un pequeño París, se dejó influenciar como es evidente por el estilo inglés. En las primeras construcciones escenográficas que se llevaron a cabo durante su mandato, y que adornaban praderas del monte y valles de barrancos, se advierte con claridad la influencia de William Chambers cuyo nuevo libro de grabados sobre Kew Gardens (1763) se hallaba en la biblioteca de Federico.

II. Rafael Argullol, La atracción del abismo. Un itinerario por el paisaje romántico (Barcelona: Acantilado, 2006), I2.

I2. Argullol, La atracción del abismo, I2.

I3 Adrian von Buttlar, Jardines del clasicismo y romanticismo. El jardín paisajista, trad. José Luis Gil Aristu (Madrid: Nerea, I993), I79-I84. 
a)

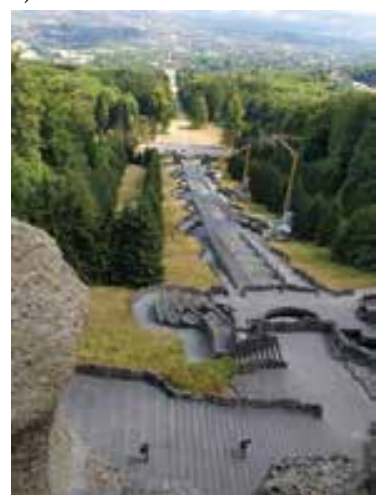

b)

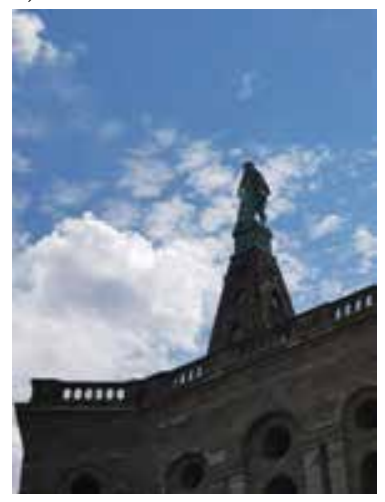

c)

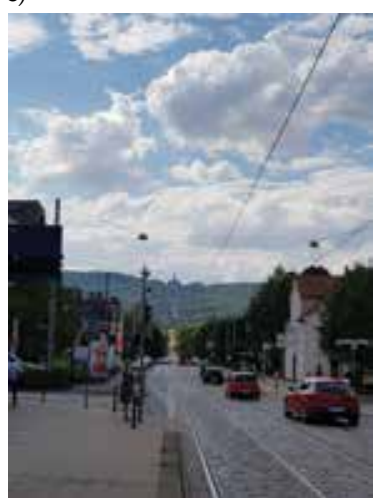

2. Hércules vigilando la ciudad de Kassel desde la ladera de Wilhemshöhe, Kassel, Alemania, julio de 2018. Foto del autor.

En el gobierno de su hijo, Guillermo IX, que tomó el poder en 1785 , todos los restantes elementos estilísticos se transformarán en paisajistas. Cuando Guillermo muere en i82I y es enterrado en el parque, se da por terminado el conjunto romántico de Wilhelmshöhe que se llevaba desarrollando a lo largo de un siglo. Esta montaña transformada en un jardín paisajista romántico presidía la ciudad e influía en las mentalidades de sus habitantes a tal punto que hasta la segunda guerra mundial, Kassel se consideraba el corazón de la sensibilidad romántica alemana (figs. 2a, b, y c).

Es de destacar que el primer edificio de Alemania proyectado para ser museo, el Museo Fridericianum, sede de documenta, sigue el palladianismo inglés (fig. 3). ${ }^{\text {I4 }}$

Con la llegada de la paz, la mentalidad y la imagen de la ciudad empiezan a modificarse influidas por un proyecto que, aunque empezó discretamente, iba a alcanzar una fuerza internacional importante.

Según nos informa la página oficial de documenta, ${ }^{\text {I5 }}$ Arnold Bode, el primer director artístico de la exposición, se propuso recuperar con el arte, el diálogo

I4. El interés sobre el palladianismo inglés por parte de Federico, se manifiesta además por el hecho que el jardinero de su corte, Daniel August Schwarzhopf fuera enviado a formarse en Inglaterra, en la década de 1780 . Von Buttlar, Jardines del clasicismo, I82.

I5. La información histórica de este apartado se recoge en su mayoría desde el sitio web de documenta, "Art of the Twentieth Century. International Exhibition," Documenta, I6 de julio al I8 de septiembre de 1955, https://www.documenta.de/en/retrospective/documenta, consultas varias entre febrero y noviembre de 2018 y de la investigación in situ en el archivo de documenta en Kassel. 
perdido entre Alemania y el resto del mundo tras la segunda guerra mundial. En 1955 el pintor y profesor universitario, nacido en la ciudad alemana de Kassel en 1900 , funda la Sociedad de Arte Occidental del siglo xx (Gesellschaft Abendländischer Kunst des Xx. Jahrhunderts) para mostrar el arte que los nazis habían tachado por "degenerado", así como las obras de la modernidad clásica que nunca se habían visto en Alemania. Bode intentaba acercar el arte a la gente y, sobre todo, a la clase obrera, por lo menos esto puede explicar su decisión de incluir la exposición en el Bundensgartenschau, una feria bienal de agricultura que por aquella época se celebraba en la capital de Hesse. La primera documenta fue una retrospectiva de los principales movimientos artísticos de la primera mitad del siglo xx como el fovismo, el expresionismo, el cubismo, Der Blaue Reiter, el futurismo... Artistas ya muy reconocidos en aquel momento o posteriormente, participaron en la exposición. Son los casos de Pablo Picasso, Max Ernst, Hans Arp, Henri Matisse, Wassily Kandinsky o Henry Moore.

Aquel primer intento de presentar el arte de las vanguardias a la sociedad alemana tuvo un enorme éxito. Bode dirigió las ediciones hasta el número 4, celebrada en 1968 .

El carácter de cada edición, en especial a partir de la d 5, es un reflejo de las ideas y la concepción que su director artístico tiene sobre el momento actual, por lo que no es sólo un fórum de las tendencias actuales en el arte sino, y eso es más importante, un espacio donde se ponen a prueba nuevos conceptos de configuración del acto expositivo. Cada documenta reflexiona, en primer lugar, sobre la renovación del discurso expositivo internacional. No se trata de una simple visión general de lo que está pasando en el arte actualmente sino de un reflejo de la sociedad y un desafío de las expectativas que ella tiene sobre el arte.

La tendencia de expansión e innovación del espacio expositivo a lo largo de todas las ediciones de documenta con el objetivo de investigar las posibilidades de una intervención social lo más amplia y representativa posible queda clara si se mira de forma esquemática qué uso se hace del espacio expositivo y social. Mi investigación en el archivo de la exposición en Kassel, durante el mes de julio de 2018 me acercó, entre otras cosas, al trabajo del profesor de arquitectura y diseño de la universidad de Kassel, doctor Philipp Oswalt. Según el profesor, las ediciones de documenta desde su nacimiento hasta hoy se pueden agrupar en relación con su percepción espacial, de la siguiente manera: D I-5, concentración e introversión; D 6-7, con algún caso de la D 4, arte al aire libre; D 8-9, intervención urbana; D IO, digitalización; y D II-I4, expansión global. 


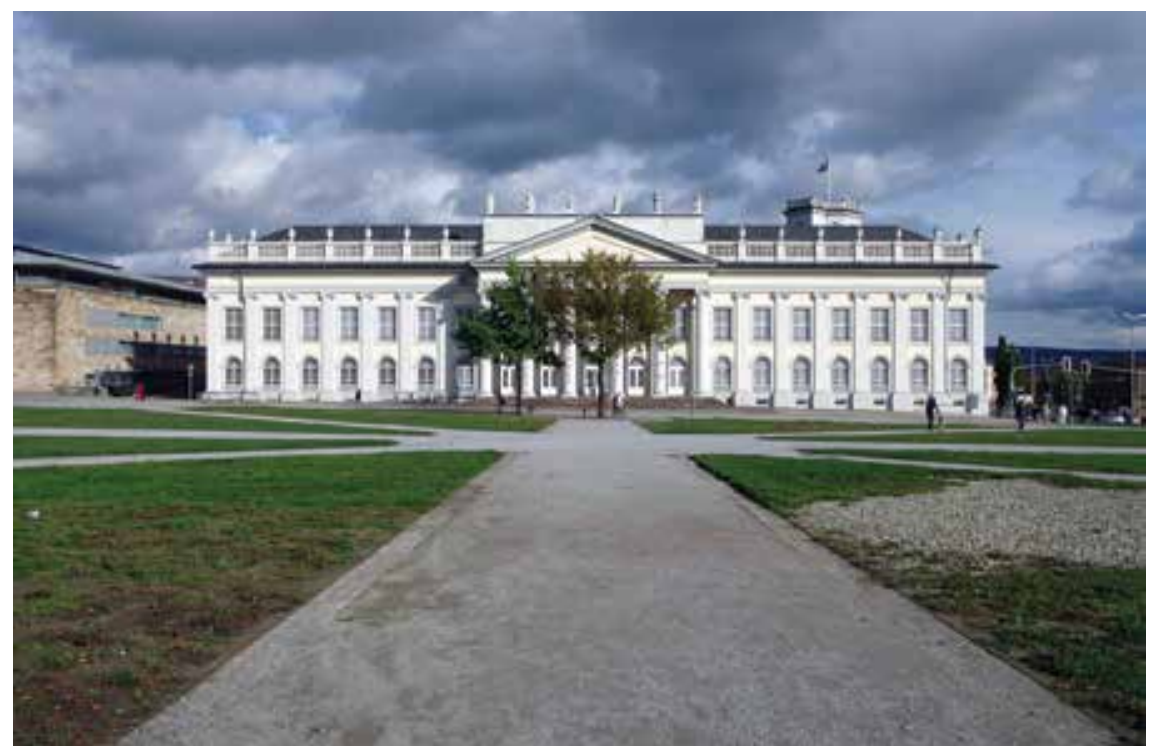

3. Museum Fridericianum, entrada principal con el primero y el último roble plantados ahí durante el proyecto artístico de Joseph Beuys "700o Oaks" para documenta 7 en 1982, Kassel, Alemania, julio de 20I8. Foto del autor.

Dicha agrupación, si se comprobara acertada, demostraría la evolución del espacio hasta convertirse en el elemento expositivo primordial para la exposición en su intento de ser un proyecto social inclusivo. Lo que sí queda claro, no obstante, es que la puesta en escena de las exposiciones, la forma que cada vez se adopta para articular un discurso expositivo concreto es, a mi modo de ver, el principal vehículo de ese desafío.

El proyecto de documenta ha podido realizar un cambio importante: la transformación de una ciudad. Kassel de ser una ciudad romántica donde la interacción entre apariencia y realidad se balanceaba sobre las laderas de Wilhelmshöhe, pasa a ser una ciudad de sensibilidad contemporánea.

Es pertinente comentar que tanto la observación sobre el romanticismo de la ciudad como el cambio que, desde mi punto de vista, se realiza hacia su contemporaneidad, no se estudian aquí en términos político-sociales — que podrían ser objeto de otra interesante investigación-, sino como sensibilidades estéticas que tanto en el primer momento, anteriormente comentado, como en el segundo, aquí expuesto, se han reflejado en la realidad de la 
ciudad y en la de su gente, mediante unas intervenciones artísticas de gran envergadura. Desde el romanticismo como sensibilidad individual y experiencia solitaria, relacionada con el desgarrador reconocimiento por parte del ser humano de su escisión de la Naturaleza, posiblemente común entre individuos de distintas clases sociales, pero no así compartida, nos movemos hacia una vivencia común entre personas de distintas clases y sujeta a ser compartida, con el objetivo de la creación de una experiencia estética de autoría común. Estoy hablando de un cambio total de paradigma, que al fin y al cabo expresa la contemporaneidad.

A pesar de las controversias, lo que es palpable es la transformación que en los últimos sesenta años está experimentando la ciudad de Kassel a raíz de la exposición. Una transformación urbana, social y mental de toda una ciudad y sus habitantes. Kassel, de ser una ciudad romántica pasa a ser una ciudad contemporánea.

Tal y como demuestran los intentos de las cuatro ediciones anteriores y de forma más pronunciada como reclama esta última edición, ha llegado el momento de abrirse al mundo y, mediante un discurso expositivo transformador, articular un mensaje internacional de renovación no sólo artística ni tampoco expositiva sino social, capaz de transformar la sensibilidad de nuestra sociedad como lo hizo con la de la ciudad alemana.

\section{I4: una expansión no sólo espacial}

Las últimas cuatro ediciones de documenta reflexionan en particular sobre la forma de exponer el arte actual y la posibilidad de expansión del espacio de su exhibición, certificando la necesidad de reconsiderar el acercamiento eurocentrista del mundo y adoptando iniciativas artísticas para la finalización de la supremacía expositiva occidental. En su intento de renovación del discurso expositivo actual desde el punto de vista poscolonial, pueden funcionar como el germen de la creación de un nuevo espacio de debate no sólo artístico sino social en el que el medio expositivo puede jugar un papel preeminente. Hasta 2017 permanecen enraizadas en Kassel, considerando al Museum Fridericianum como su verdadero hogar, pero Adam Szymczyk ${ }^{16}$ recoge el testigo como

I6. Adam Szymczyk (Polonia, I970) es el director artístico de la última edición de documenta. Crítico de arte y curador de exposiciones, ha sido director de la Kunsthalle Basel desde 2003 hasta 20I4. En I997 cofunda la fundación Galería Foksal en Varsovia y en 20II se le concede el 
director artístico de la D I4 y se aventura con una nueva propuesta más atrevida que, a mi modo de ver, hará avanzar la exposición con un paso de gigante.

En sus últimas ediciones documenta deja clara la libertad "artística" que ofrece a su director "artístico" para decidir el camino a seguir, las propuestas por hacer e incluso la forma de hacerlas, sin embargo, para la organización de la D I4 Szymczyk establece una pregunta clave: ¿por qué no libertad sin la determinación de "artística"?

El nuevo director quiere aprovechar la oportunidad que esta edición le ofrece para transformar lo que hasta ahora era la "más famosa y discutida exposición de arte contemporáneo" en un espacio de debate y experimentación no sólo estética sino política, económica y social con el vehículo de la creación artística actual. Szymczyk entiende la D I4 como un espacio social de lucha para sobrevivir en un entorno internacional hostil caracterizado y controlado por una serie de circunstancias adversas que se utilizan por parte de ciertos poderes de manera, como mínimo discutible: la deuda soberana que sirve como excusa de violencia económica sobre una parte de la población europea que pierde libertades básicas, las oleadas de emigración como resultado de la guerra en Siria para las que Europa (agente principal del conflicto) mira hacia el otro lado, los absolutismos e inmovilismos de poderes políticos concretos, los extremismos nacionalistas y el surgimiento de una fuerte sensibilidad neocolonialista... todos estos factores conforman un escenario social muy complicado frente al que el arte y su forma de exponerse no pueden quedarse silenciados. La documenta de Szymczyk quiere crear las posibilidades y circunstancias de respuesta y ayuda a la creación de una sociedad nueva que se revela frente a todo lo anterior.

Esta edición intenta romper con todo lo visto en las anteriores y establecerse como salida reflexiva sobre la situación política actual basada en los principios y mecanismos del neoliberalismo y el neocolonialismo que intentan determinar la vida y la existencia de todos los que vivimos en el planeta.

Según Szymczyk, D I4 es una "excelente oportunidad para preguntarnos sobre el papel que puede jugar la producción artística dentro de este aparentemente bien afilado sistema de producción y consumo, visualización e inversión del aparato occidental". ${ }^{17}$

premio Walter Hopps por sus logros curatoriales. Según The New York Times se trata de uno de los "superstars de los curadores".

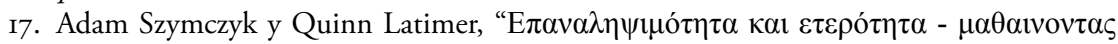

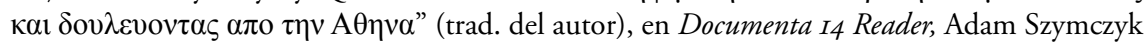
(Múnich/Londres/Nueva York: Prestel Verlag, 2017), 19-42. 
El traslado geográfico e ideológico del centro de la organización desde su, hasta ahora, indiscutible base alemana a la capital de una crisis mundial tan discutible que lideró las manifestaciones contra ella, llega como el resultado de la necesidad de acción en el tiempo y el espacio actuales, frente a un orden sociopolítico que se está estableciendo en todo el mundo de forma muy agresiva, con la excusa de esta crisis económica. Szymczyk parece decidido y convencido: no se puede intentar contar, comentar o explicar el mundo desde la tranquilidad de Kassel y su exclusivamente occidentalizado punto de vista, pero tampoco sería acertado intentar hacerlo desde un único punto de vista, limitado y excluyente. En D I4 con el lema "Learning from Athens" (Aprendiendo de Atenas), el camino es distinto: "La unidad clásica de espacio, tiempo y acción de una exposición se cuestiona desde su raíz [...] No existe ni un inicio, ni un final unívocos y determinantes". ${ }^{8}$

La exposición del arte no es una demostración abstracta y confusa de unas realizaciones que pueden desarrollarse en cualquier marco arbitrario, tal y como las estrategias de marketing del mundo de la globalización intentan establecer. A pesar de la idea de una existencia uniforme, idéntica y global promovida por las políticas centralistas, el arte es una experiencia personal tanto corporal como mental que debería llegar a ser compartida y que cuyo marco espacial y temporal sí importa.

Las últimas ediciones de documenta adoptan iniciativas para la finalización simbólica de esta supuesta supremacía occidental aunque permanecía enraizada en Kassel que consideraban como su verdadero e indiscutible hogar de exposición. Szymczyk —a diferencia de las inmediatamente anteriores ediciones de la exposición, cuyas propuestas de internacionalización espacial se quedaban en unos intentos teóricos bastante limitados - entiende y atiende a Atenas y Kassel por igual, en cuanto a la devoción de la exposición en cada una de sus dos sedes, lo expuesto aquí y ahí, los actos paralelos, entre otros como si, en palabras de Antonin Artaud, de un "teatro y de su reflejo" se tratara. La intención es clara: crear un "Parlamento de los cuerpos" transnacional y transformable que se componga de todos los que se juntan en la documenta y después se dispersan para crear otros "Parlamentos" de nuevo poder en distintos lugares y tiempos. ${ }^{19} \mathrm{Al}$ salir de su zona de confort y expandiéndose en el tiempo y

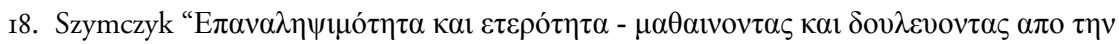
A $\theta \eta v \alpha "$ (trad. del autor), 27.

19. El término "Parlamento de los cuerpos" (en griego: Vouli ton Somaton) hace referencia 
en el espacio que separa (¿o quizás une?) las dos sedes, D I4 es una oportunidad de diálogo abierto en la sociedad y continuo en el tiempo.

A pesar de lo que en la teoría se está cuestionando desde hace varias décadas, la gran mayoría de las exposiciones y su praxis se están creando desde un punto de vista anclado a cánones decimonónicos, claramente occidental, por no decir norte-europeo y sin lugar a dudas, excluyente. La idea de un arte actual poscontemporáneo y socialmente comprometido que está ganando terreno cada vez más, no puede dejar indiferentes a los agentes que se encargan de exponerlo. Me resulta muy difícil olvidar en este punto a Nicolas Bourriaud y considerar que el objetivo de este arte socialmente comprometido pueda ser otro que la creación de relaciones. Relaciones entre los artistas, los espectadores y los demás agentes del arte que pueden llegar a ser consideradas como la obra artística final.

Creo que D I4 se mueve en el mismo camino y en este sentido su praxis es nueva. En palabras de su director artístico:

expandiendo el tiempo y el espacio del continuum de una exposición, entre dos ciudades y a lo largo de un ampliado periodo de tiempo, d I4 no sólo se determina por su creación y el diálogo que establece, sino por la posibilidad de continuación de ambos [...] Al presentar prácticas y conocimientos locales del resto del mundo, en Kassel, mediante Atenas, queremos cuestionar y desafiar la establecida mentalidad de la blanca, masculina, nacional y colonial supremacía que sigue predominando en las prácticas y conocimientos locales del resto del mundo. ${ }^{20}$

La última edición de documenta es muchas cosas, pero sobre todo es acción en el espacio y en el tiempo actual con el objetivo de crear relaciones frente a un orden sociopolítico que de manera agresiva viene como un fantasma desde el pasado para establecerse de nuevo.

D I4 ofrece posibilidades de reacción al abogar por una participación amplia y conjunta desde focos de actuación múltiples y distintos. La expan-

a uno de los programas públicos de D I4 que actuaba contra la transformación de los cuerpos en masa y la transformación del público en objeto de comercialización, dando valor a la individualidad y el poder que puede emerger cuando se unen distintas individualidades con conciencia de su valor como tales. Su construcción empezó en Atenas, siete meses antes de la inauguración de la exposición, con unos "ejercicios de libertad" en el Centro Municipal de las Artes en el Parko Eleftherias (Parque de la Libertad) y continuó su trabajo en Kassel en la rotonda del Museum Fridericianum.

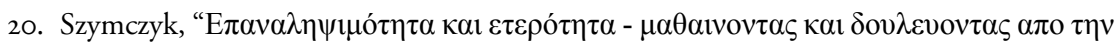
A $\theta \eta v \alpha "$ (trad. del autor), 29-30. 
sión que propone no es sólo un mero cambio del lugar de exposición. Al exponer desde Atenas a la vez que desde Kassel, Szymczyk quiere demostrar que existe la posibilidad de una participación social más amplia y una intervención ciudadana más generalizada en lo que muchos de nosotros queremos que sea el arte actual. El espectador pide reflexionar acerca de las propuestas de los artistas mediante posibilidades expositivas que amplían sus propios horizontes hacia espacios personales. Cada una de sus obras y su exposición es una oportunidad de expansión de nuestro propio espacio personal, reducido y cerrado hacia experiencias más participativas y creativas. Se trata de pequeños momentos de "expansión" personal que pueden llegar a acercarnos a otras individualidades para que todos formemos parte de un conjunto social "expositivo", que mediante la creación de relaciones estéticas, sea capaz de articular un discurso diferente al oficial.

A continuación se comentan algunas de las obras en las que tuve la oportunidad de "participar" en primera persona. Se trata, entre otras cosas, de claros ejemplos de experimentación acerca del espacio expositivo tradicional y mi lectura de ellas es desde este punto de vista. Si algo ha quedado muy patente en la D I4 es que el arte actual pide ser expuesto, visto y entendido en un contexto distinto a lo institucional y mucho más amplio de lo que hasta ahora se ha ido haciendo.

\section{Los "paseos"}

Con intención de ver cómo se puede poner en práctica la participación del espectador en la evolución y conclusión del acto expositivo, D I4 implanta la idea de los "paseos" por los espacios de las exposiciones. Se trata de actos participativos en los que un miembro de un equipo de bailarines de danza contemporánea junto a espectadores que deciden participar y previamente lo han manifestado así a la organización, forman un grupo para visitar el espacio. El grupo tiene la posibilidad de crear su propio itinerario de investigación y diálogo con la excusa de la exposición mientras se acercan a ella la recorren y la descubren con la ayuda del miembro del equipo de bailarines que no hace de guía sino que, como parte del equipo, representa el punto de vista de la organización.

En forma de un coro del teatro clásico griego con su "principal", todos los que decidimos participar en esos "paseos" por los distintos espacios nos damos cuenta de que de repente pasamos de ser unos desconocidos a formar parte 
de un coro que a modo de representantes de la sociedad, le damos voz, dialogamos con el artista o el curador, le recomendamos cosas y a veces le adivinamos el porvenir. Hemos decidido ser una parte activa del proceso expositivo tal y como lo era el coro del teatro griego en la trama teatral y relacionarnos con los agentes de la exposición de manera parecida a cómo se relacionaba el coro con el protagonista del drama. Se crea así una multiplicidad de voces que, añadidas a la del artista y el curador, pueden seguir haciendo preguntas, abriendo diálogos, creando mitologías y contando historias verdaderas o ficticias más allá del tiempo geológico y del espacio tridimensional de la exposición.

El guiño que Szymczyk hace aquí al Dadá parisino de los principios de los años veinte y más concretamente a sus "excursiones y visitas", es más que claro. El Dadá de París, que se construyó sobre las innovaciones del Cabaret Voltaire (I915-1917) del Dadá de Zúrich, decide hacia la primavera de I92I, sacar el performance fuera del contexto del cabaret y llevarlo al espacio público extrainstitucional. Busca involucrar al público usando el espacio público, proyectando los eventos Dadá a un nuevo tipo de ámbito más allá de las salas. La primera de aquellas "excursiones" fue programada para el I4 de abril de I92I a las 3 p.m., en una reunión en el atrio de la iglesia de Saint Julien-le-Pauvre. En lugar de llamar la atención hacia sitios pintorescos o lugares de interés histórico, el objetivo era hacer un sinsentido de la forma social de los recorridos guiados. ${ }^{21}$ Para André Breton, uno de los pilares teóricos del Dadá, significaba que el movimiento entrara al ámbito público rompiendo con las convenciones teatrales, para crear situaciones donde el público sería confrontado con un nuevo tipo de acción y espectaduría artística: "al unir pensamiento con gesto, Dadá ha dejado el ámbito de las sombras para aventurarse hacia terrenos firmes". ${ }^{22}$

He podido participar en dos de esos intentos de creación de una obra de autoría compartida en un espacio expandido hacia lo temporal y lo social, que a mi modo de entender son esos "paseos".

El Odeón ateniense (también conocido como Conservatorio ateniense), institución que hasta ahora custodiaba obras de arte contemporáneo y que a la finalización de la D I4 se trasladarán al recién inaugurado Museo Nacional de Arte Contemporáneo (en adelante EMST), fue el escenario de la más interesante e interactiva de estas participaciones. Un grupo inicialmente heterogéneo formado por una pareja de jubilados alemanes de Kassel, que habían visto casi

2I. Se puede ampliar la información sobre las “excursiones” Dadá, en Claire Bishop, Infiernos artificiales. Arte participativo y políticas de la espectaduría, I09-I20.

22. André Breton, Artificial Hells, I38, citado en Bishop, Infiernos artificiales, II5. 
todas las ediciones de la documenta, dos mujeres canadienses de ascendencia griega, que visitaban Atenas, cuatro amigos italianos, que nunca antes habían visto una exposición de arte contemporáneo, algunos griegos entre ellos uno que vive en Barcelona y que actualmente está reproduciendo aquella experiencia en un intento de darle nivel doctoral... y dos amigos mexicanos, que llegaron corriendo los últimos por haberse perdido en las bulliciosas calles de la capital griega, junto con nuestro "principal" y siguiendo sus instrucciones formamos una fila uno detrás del otro. La idea era pasear alrededor del edificio del museo, rodeándolo antes de entrar. Cada vez que alguno viera o escuchara algo gracioso o divertido tenía que salir de la fila y ponerse al final de ella mientras el rodeo continuaba (figs. $4 \mathrm{a}$ y b).

Un recorrido que al principio empezó algo frío y desconcentrante y que en realidad no debía de tardar más de diez minutos en concluirse, duró más de media hora al final de la cual aquel grupo heterogéneo de personas desconocidas se había transformado en una microcomunidad de conciencias individuales con una cosa en común: su declarada intención de entrar en el espacio, ver de cerca la propuesta expositiva de unas obras, comentarla, discutirla y de alguna manera al salir llevársela cada uno a su lugar de procedencia.

Una vez dentro del Odeón, el grupo fue más activo comentando vivamente lo expuesto, intercambiando opiniones y preguntando cosas. Las intervenciones y las reacciones por nuestra parte ante aquel hecho expositivo, fueron interesantísimas, divertidas y creativas. Como Bishop observa refiriéndose a las "excursiones" Dadá, aquel deseo por la atención de la audiencia implicaba "un desplazamiento importante en la modalidad de relacionarse con la audiencia por parte de Dadá”. ${ }^{23}$ Me parece casi obvio el deseo de vincularse con el público de forma parecida, por parte del director de D I4. Breton sugería que "los observantes debían encontrar una continuidad entre la obra de arte y sus vidas [...] una manera de forjar una conexión más cercana entre el arte y la vida” ${ }^{24}$ y a mí me parece que Szymczyk intenta fomentar lo mismo aquí. Cuando aquella visita se había acabado y todos salíamos de aquel espacio para seguir nuestros caminos personales, algo me decía que el objetivo del director artístico se había cumplido. Aunque no intercambiamos teléfonos, cuentas de Facebook o Instagram, estoy convencido de que cada uno de quienes formamos aquella microcomunidad instantánea llevamos esa experiencia "a la calle", a nuestro espacio personal, y cada

23. Bishop, Infiernos artificiales, II6.

24. Bishop, Infiernos artificiales, II6. 
a)

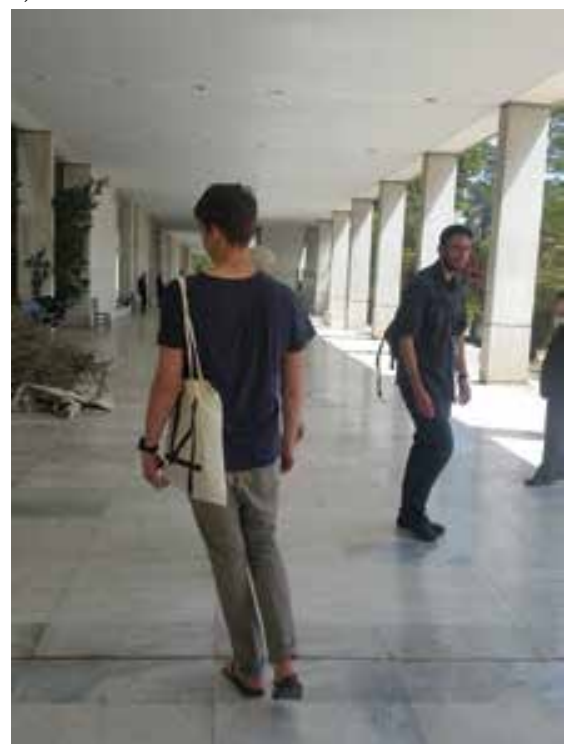

b)

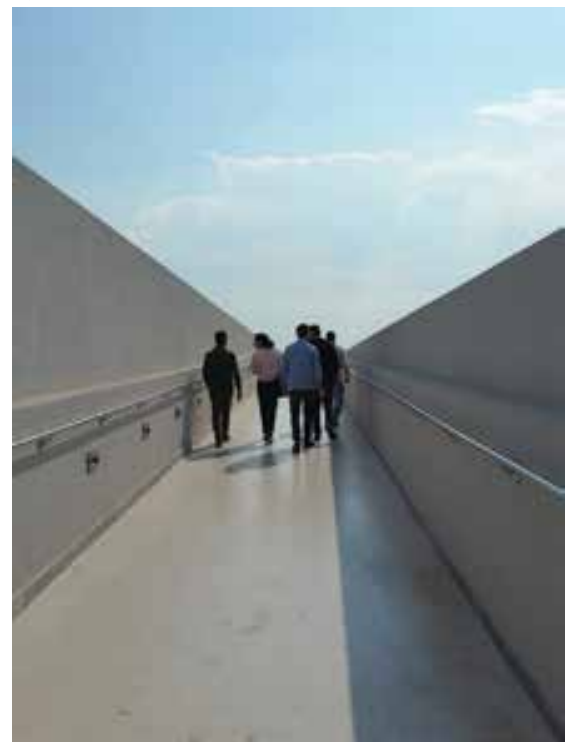

4. a) Paseo I, Odeón, Atenas, Grecia, I4 de abril de 20I7. b) Paseo 2, Emst, Atenas, Grecia, I5 de abril de 20I7. Fotos del autor.

uno a su manera sigue compartiéndola, expandiéndola en el tiempo y creando un espacio expositivo ampliado con ella, dando lugar, a la vez, a una nueva obra de arte más amplia y duradera de las que se visitaron en aquel momento, que es la relación estética creada entre nosotros con la excusa de la exposición.

\section{El Partenón de los libros}

La artista Marta Minujín (Buenos Aires, 1943) presentó en D I4 su obra El Partenón de los libros (The Parthenon of books) como parte de su proyecto. La caída de los mitos universales con la que la artista se apropia de símbolos monumentales de todo el mundo para reproducirlos, romperlos en pedazos y redistribuirlos entre el público.

Según Pierre Bal-Blanc, la artista intenta en cierto modo devolver a esos símbolos su estatus de ofrendas, confiscado por la capitalización e institucionalización de la sociedad actual. Para El Partenón de los libros empezó en 1983 en Buenos Aires, una empresa de recogida de libros prohibidos o demonizados 
por la junta militar del país. La artista invitó a la gente que escondía esos libros en sus casas a ofrecerlos para la construcción de una réplica del templo griego a escala natural. La obra se presentó por primera vez en Argentina y la operación se repitió en 2017 en Atenas y Kassel en el marco de la D I4.

Con esta obra, Minujín propone la reanimación de las ceremonias participativas de sociedades antiguas, como respuesta a la privatización de la propiedad pública que, mediante la especulación de la deuda soberana, fomenta la supresión del sector público, creando escasez social.

La obra ha sido un proyecto en construcción que empezó antes de la exposición en Atenas y que duró después de su clausura en Kassel en septiembre de 2017. Los agentes de la exposición lanzaron un mensaje abierto a toda la gente que guardaba libros prohibidos, invitándola a donarlos para la construcción del monumento.

Utilizar libros como material escultórico no es algo novedoso o rompedor en sí. Muchos artistas antes han reflexionado acerca del valor simbólico del libro como contenedor de ideas e ideologías igual que como objetivo de persecución u objeto de propaganda. Es sumamente interesante, no obstante, el interés de Minujín y la manera obvia y directa que adopta para poner en práctica la tan deseada participación del espectador en la conclusión de la obra. En este sentido veo una conexión muy clara con las primeras intervenciones-performances del artista británico John Latham, padre del movimiento APG, quien a partir de 1958 usa los libros como material artístico a la vez que objeto para actos participativos. Las publicaciones, para él, se convierten en monumentos, son quemadas, incorporadas en los ensamblajes, pero la que creo que tiene mayor interés, desde el punto de la participación, es su performance de 1966 Still and Chew. Bishop describe el performance así: "él y varios de sus estudiantes masticaron una copia de Arte y cultura, de Clement Greenberg, prestado de la biblioteca de la escuela de arte St. Martins. Cuando la biblioteca solicitó que regresara el libro, Latham lo hizo, pero como una redoma de páginas masticadas". ${ }^{25} \mathrm{El}$ performance fue el motivo de despido de Latham de la escuela, no obstante los restos de la "obra", bajo el título Art and Culture [I966-1969], fueron adquiridos por el MOMA en 1970 .

Más allá del sentido filosófico de aquel performance, Latham creó una obra que no son los restos adquiridos por el museo estadounidense sino la relación creada por el acto participativo y el diálogo surgido a raíz del performance. El

25. Bishop, Infiernos artificiales, 265. 
espacio donde la obra se expone no es una sala del moma sino el espacio social de diálogo y reflexión que abrió y que dura en el tiempo. Latham creó una obra "a largo plazo" y Minujín de alguna manera influida, se centra en demostrar que pueden existir proyectos en los que la participación del espectador puede ser realista, efectiva y sobre todo necesaria, creando así una obra de autoría común, que va más allá de la fabricación de un mero objeto, se expande en el tiempo y tiene una larga vida, haciéndonos reflexionar sobre la naturaleza misma de la obra.

¿Cuál es la obra que Minujín crea con la ayuda de la gente que decide participar y puede aportar en el proyecto? ¿Es la réplica del edificio clásico griego? ¿Es su interpretación del edificio por medio de esta reproducción? ¿Dónde se expone esta obra? ¿Cuál es su espacio?

Me resulta muy difícil no entender como obra la relación social que se crea alrededor de esa reconstrucción, relación caracterizada por un claro valor estético, y me es imposible entender como espacio de su exposición, sólo el espacio físico donde este objeto se encuentra, obviando el espacio político y cultural que se crea con su realización.

La deconstrucción de la obra viene a apoyar mi manera de entenderla: el 9 de septiembre de 2017 a las I2.00 horas del mediodía, la organización de la D I4 invitó a todos los que quisieran tomar parte en la celebración de la finalización del proyecto. Los espectadores participaron de distintas maneras en este acto, leyendo fragmentos de los libros prohibidos en distintos idiomas, recitando versos propios suyos, presentando coreografías, tocando música o simplemente escuchándola dentro del "Partenón" acompañados por la artista y otros miembros de D I4. Una vez acabado el "acto deconstructivo" empezó la demolición del edificio para que los libros pudieran volver a manos del público y ser releídos. El día siguiente, la artista empezó la redistribución de los libros a los habitantes de la ciudad de Kassel y a los demás visitantes de la exposición.

¿Acabó la obra con su deconstrucción? ¿Cuánto tiempo duró? ¿Fue realmente una obra efímera?

Estoy convencido de que ni el objeto artístico, ni su espacio de exposición ni el tiempo de ella, son los que inicialmente parecen ser. Si la obra es la relación social creada alrededor del objeto, entonces el espacio de ésta no es el físico y su tiempo no es el geológico. La obra se expande creando un espacio propio más allá de las tres dimensiones, ampliado en la esfera política, cultural e histórica y en un tiempo capaz y posible de ser expandido en el presente y en el futuro a través de las experiencias de las individualidades que participaron en su creación. 


\section{Las puertas de EMST}

A mediados del siglo xix, después de la revolución griega contra el Imperio Otomano y la construcción del Estado moderno griego en forma de monarquía, llega desde Baviera, el recién nombrado rey Otto con la familia real. En un intento de implantar una clase aristocrática en el nuevo Estado europeo, a la imagen de otros países del Nuevo Régimen del Viejo Continente, acompañan al rey varias familias de nobles alemanes movidas por las ideas del romanticismo imperante en aquella época y aprovechando las oportunidades de enriquecimiento en el nuevo país que surgiría en las tierras de la "cuna de la democracia".

Entre ellas se encuentra la familia del ingeniero Fuchs, cuyo hijo, Johann Karl Fuchs (luego llamado Fix), funda en I864 la primera empresa de producción de cerveza en Grecia. La marca crece de forma rápida durante las siguientes décadas, y bajo la dirección del hijo de Johann Karl Fix (en griego Károlos Fix), la marca llega a ser la cerveza más famosa en los países balcánicos y del Mediterráneo oriental, donde prácticamente tenía el monopolio.

A pesar de su éxito inicial, el paso del tiempo, la competencia de otras marcas que iban surgiendo en el entorno y los importantes cambios en la situación política y económica del país, llevaron a la Cervecería Fix a la quiebra hasta su desaparición final en 1983 más de cien años después de su fundación. No obstante, la fábrica cervecera dejó a la ciudad de Atenas un importante patrimonio arquitectónico de varios edificios industriales, destacando entre ellos la emblemática Cervecería Fix de la avenida Syngrou.

El edificio, diseñado por el visionario arquitecto Takis Zenetos (1926-1977) y proyectado en colaboración con el arquitecto Margaritis Apostolidis (I9222005), se completó en I96I, renovando la anterior fábrica de I864, según el estilo de la Nueva Bauhaus y dotándole con elementos tan característicos del estilo como la pureza de su forma, la claridad de la construcción, su flexibilidad y la clara voluntad de sus arquitectos en la participación del usuario en la configuración final del entorno. La fábrica, que funcionaba inicialmente las 24 horas, se diseñó para que el trabajo en el interior pudiera verse por los paseantes desde el exterior, siendo esto mucho más espectacular durante la noche cuando el interior se iluminaba. Otro rasgo de su diseño, que se englobaría en la flexibilidad de la construcción, fue la capacidad de futuras expansiones horizontales del edificio, sin interrupción de la producción. ${ }^{26}$ 
En 1994, cuando el edificio llevaba más de una década abandonado, se reutiliza por la recién formada Atticó Metro, s.A. (la empresa privada del Metro de Atenas) que demuele la mitad norte de él para crear un espacio público abierto alrededor de la parada del Metro que llevaba el nombre fix y que se inauguró en 2000.

El емST que iba recolectando arte contemporáneo griego e internacional desde el final de la segunda guerra mundial, hasta el 2000, y que hasta aquel momento iba presentando sus colecciones en distintos espacios (entre ellos el Odeón Ateniense), firmó en 2002 una licencia de 50 años con el Atticó Metro, s.A. para la remodelación y uso del resto de la fábrica Fix, como su sede.

Una destacadamente acertada y exitosa renovación del edificio se llevó a cabo por los arquitectos del despacho 3SK-Stylianidis Architects, en colaboración con I. Mouzakis \& Associate Architects, Tim Ronalds Architects y K. Kontozoglou quienes renovaron tanto la fachada este como el interior del edificio (figs. 5a, b, c y d).

En estrecha colaboración con EMST, los curadores de la D I4 imaginaron una exposición que transmitiera a toda la extensión del edificio una sensación de economía libidinal del espacio vertical del mismo, centrándose en el alcance del edificio en los sentimientos del visitante.

A medida que se sube por las escaleras mecánicas hacia el tejado del edificio, la atracción por el espectáculo del tejido urbano ateniense, desarrollado en el exterior, presidido por la omnipresente Acrópolis y que se deja ver desde el interior a través de los grandes ventanales que en otras épocas dejaban ver el proceso de producción de cerveza en el mismo interior. Se establece una especie de diálogo entre visitante y paseante en el que no está claro quién es la obra y quién el espectador. Cuando se llega al último piso, frente al ventanal que se encuentra delante de ti, con el inevitable Partenón marcando la distancia en el fondo, sólo entonces el espectador se entera de que ha ido formando parte de lo expuesto para los transeúntes.

¿Expuesto? De pronto el espectador se da cuenta de que todo este tiempo no ha visto ninguna obra... Nada de arte. Miras a tu alrededor y lo único que ve son ventanas que enmarcan la urbe en una especie de tableaux vivants, alguna fotografía de la antigua fábrica, vigilantes delante de unas puertas cerradas

Map Booklet (Múnich/Londres/Nueva York: Prestel Verlag, 20I7), 4; de mi visita personal durante la documenta, en forma de "paseo" y de la página web oficial del EMST http://www.emst.gr/en/ museum/the-fix-building, consultado el 26 de junio de 2018. 
a)

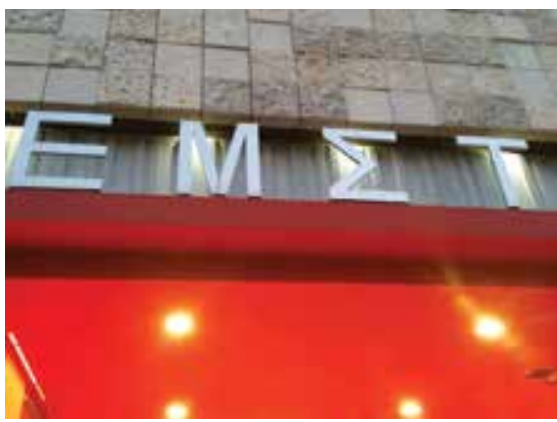

c)

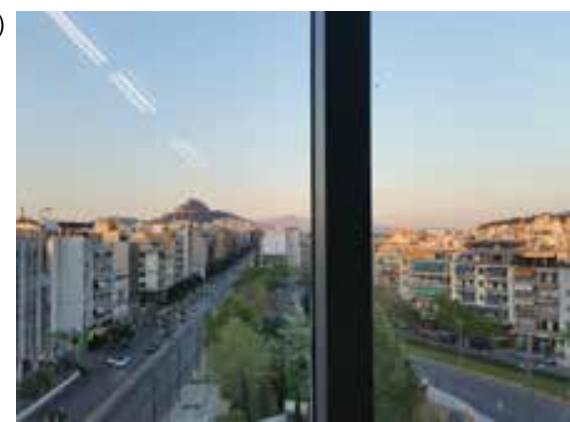

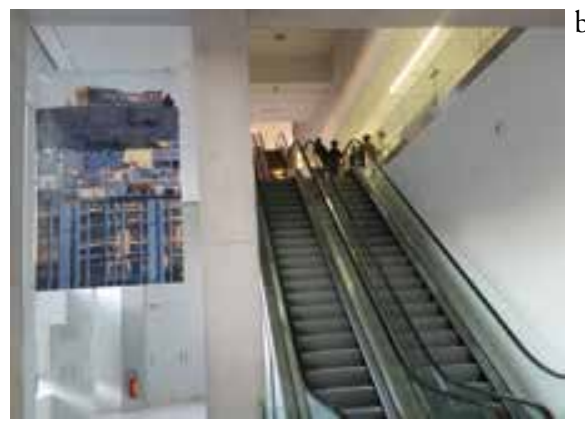

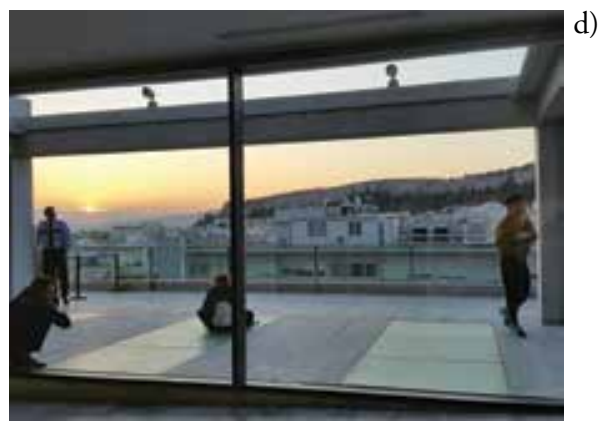

b)

d)

5. emst (Museo Nacional de Arte Contemporáneo), Atenas, Grecia, abril de 20I7. Foto del autor.

que al principio parecen las puertas de los servicios, y poco más... Es cierto que la sensación del espacio interior mezclándose con el interior y el diálogo establecido entre el paseante de la ciudad y el espectador es muy agradable, pero... ¿es esto, todo?

¡Tiene que hacer algo! Mira a su alrededor y una vez acostumbrado al espectáculo que se desarrolla dentro y fuera del edificio, con la ayuda del fuerte sol ateniense, se da cuenta de que aquellas puertas vigiladas se pueden abrir... El primer paso que da hacia una puerta, la insegura y algo incómoda sonrisa que le dirige al vigilante, su mano encima del manillar y su primer paso para entrar en el espacio hasta ahora oculto, todo es una declaración de intenciones. Ya no es un simple visitante pasivo. La transformación del espacio lo reta y su libre decisión de abrir la puerta, pasar el linde que ésta crea entre los dos espacios e investigar el otro lado demuestra que acepta el reto. Ya es cómplice en la conclusión de la exposición. 
Detrás de las puertas cerradas que hay en cada piso se abre un mundo entero. Interminables salas de exposición albergan propuestas que decide investigar. Es, a mi parecer, una interesantísima propuesta de la museografía actual con la que se reflexiona sobre el uso creativo del espacio físico: cómo éste puede aprovecharse para crear un nuevo espacio mental, distinto para cada uno de nosotros pero listo para compartirse, formando en estrecha colaboración con su usuario, un nuevo espacio expositivo que nace en las cuatro paredes del museo, pero que se expande más allá de ellas.

En la hipotética pregunta de si la antigua fábrica puede todavía producir algo mi respuesta es sí: ciudadanos coherentes y participativos.

Actualmente, el museo está cerrado para una nueva remodelación de su espacio y la adaptación de éste con la colaboración de la fundación Stavros Niarchos. Según he podido saber, después de contactar con agentes de la institución, uno de los temas de debate de la remodelación es precisamente el tema de las puertas cerradas, hecho que me demuestra que aquella decisión durante el tiempo que el museo formaba parte de las sedes de D I4, no era casual sino pensada. Espero que ahora se decida por la opción acertada...

\section{De la sala de exposición al espacio participativo}

Si miramos hacia los comienzos de la creación de las instituciones museísticas como centros que exponen el arte y analizamos su papel en relación con el poder que las instauró, no podemos dejar de observar que dichas instituciones se utilizaron por parte de ese poder como herramientas de creación de un discurso concreto y del establecimiento de unas relaciones muy precisas entre él y la sociedad. El poder detrás de ellas se autolegitimaba con base en el conocimiento que reunía y se autoproclamaba como hegemónico mediante el discurso que creaban.

El siglo xx en el arte está marcado por el cambio de paradigma "museoinstitución de conocimiento" al de "museo-institución de creación de relaciones entre verdad y poder". Es el momento de investigar si ése es el único tipo de relación posible. ¿Puede el museo crear nuevos vínculos entre distintas realidades?

Michel Foucault en su libro de 1975 Surveiller et punir: Naissance de la prison (Vigilar y castigar: el nacimiento de la prisión) hace una interesante reflexión sobre las cárceles, los asilos y las clínicas del siglo XviıI, incluyéndolas en las 
que denomina "instituciones disciplinarias de encerramiento". Según el filósofo francés, en aquel momento el espacio del castigo se traslada de la plaza pública a la cárcel, pero sigue sirviendo a los intereses del poder, y que lo que dictan, como práctica de reinserción es el castigo.

La idea la recoge el historiador del arte Douglas Crimp quien en su libro de 1993 On the Museum's Ruins (Sobre las ruinas del museo) — respecto de las teorías de Foucault- comenta que existe también una institución con características de encerramiento, el museo. Observa que durante la misma época, el espacio de la exposición se traslada desde la colección palaciega al espacio museístico abierto al público, sin embargo, la nueva institución sigue ejerciendo un poder disciplinario mediante reglas, para crear un público disciplinado. Ese público se veía obligado a autoposicionarse en la sociedad mediante su ubicación en el espacio de la sala museística.

Recientemente el historiador Tony Bennett se posiciona en relación con las ideas de Crimp, opinando que en el caso del museo no se puede decir eso de forma tan abierta. En su texto "El complejo expositivo" de la edición Reader de D I4, entiende el museo como una institución que se forma mediante relaciones de vigilancia, ayudadas por un conjunto de tecnologías culturales con el objetivo de crear una autocontrolable colectividad ciudadana para la exhibición del poder y que, aunque no tiene las mismas características que las instituciones de encerramiento de Foucault, es muy fácil convertirse en una de ellas, como dice Crimp, si las relaciones creadas ahí siguen siendo las basadas en la "verdad" y el poder.

En la introducción del presente artículo comentaba que el pensamiento poscolonialista irrumpió con fuerza en el panorama teórico y social poniendo las bases para una revisión de la Historia, dando primacía a las pequeñas historias locales con el objetivo de incluir en esa revisión al "otro", hasta ahora silenciado. Sin embargo, aquellos intentos de establecer una sociedad abierta y enriquecida por la diferencia con la ayuda de esta teoría poscolonialista, se ven socavados a principios del siglo XxI por el surgimiento de una crisis económica internacional. El poder que la crea aprovecha las dificultades provocadas por ella para cerrar filas y volver a establecer unos principios neoliberales y neocolonialistas. Ayudado por los nacionalismos excluyentes y sus intentos de establecer fronteras y construir muros, el poder con el miedo como arma básica en su intento, pone de nuevo las antiguas bases en el establecimiento de relaciones entre él y la verdad. Tal y como observa A. Szymczyk: "El miedo es la herramienta básica del neoliberalismo precisamente porque se capitaliza 
más fácilmente que el deseo o la alegría" ${ }^{27}$ Hemos entrado en el siglo XXI en unas circunstancias como mínimo preocupantes.

En un momento histórico como el actual, en el que, como se está demostrando cada día, reina la irresponsabilidad, la sinrazón y el beneficio micropolítico a favor de personas corruptas o potencialmente corrompibles; en una época en la que el argumento y la cordura son borradores por el grito de la masa y el insulto lanzado hacia el adversario con demasiada facilidad, es momento de tomar posición y actuar.

Hoy, cuando los que utilizan términos como "facha" o "nazi" para dirigirse al que piensa diferente, son demasiado irresponsables o demasiado jóvenes para poder saber el verdadero significado de estas palabras y el potencial destructor que tienen esas ideologías, no podemos quedarnos como simples espectadores.

Estos días, cuando términos como territorio, frontera y espacio, se utilizan por parte de un poder que se ha demostrado demasiado pequeño para gestionar una situación muy complicada, como banderas para separar a las personas en vez de unirlas, en esta coyuntura internacional crítica de un sistema político-cultural en clara decadencia que tiene como idea principal hacer el país "great again", el arte debe tomar partido y decir mucho.

Cuando todos los intentos de recuperación social han fracasado, creo con fervor que la filosofía y, más claramente la ética y la estética son nuestros únicos salvavidas.

Unir no significa unificar y mucho menos homogeneizar. Unir significa abrir, ampliar y expandir. Expandir nuestro espacio y expandirnos hacia el prójimo con un deseo claro: conocerle y enriquecernos de él, ofrecerle nuestras ideas y aprender de las suyas. No "tolerar", sino crear juntos un espacio ampliado y expandible hacia una sociedad participativa.

Durante las últimas décadas, el arte parece estar sospechosamente callado o ¡es que la forma de exponerse la calla? Ciertas líneas de investigación sobre su exposición están demostrando que un espacio nuevo, más allá del espacio físico y del tiempo geológico, es posible. Propuestas expositivas actuales se mueven hacia esta dirección demostrando un claro interés de crear en vez de destrozar. Unir antes que separar. Unir sensibilidades diferentes para crear algo nuevo, fresco y dinámico que respeta, acepta y fomenta la diversidad. No la "tolera" sino la necesita para existir.

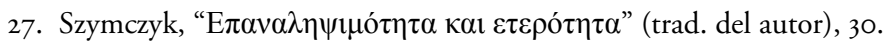


Como he comentado antes, he intentado demostrar aquí que el arte y su exposición, mediante el empeño de sus agentes, se mueven hacia esta dirección, teniendo propuestas actuales, factibles y reales que pueden abrir un nuevo camino.

¿Se demostrarán las instituciones a la altura?

Habitualmente el arte y sus instituciones, incluyendo la documenta en sus primeras ediciones, tratan al espectador no como partícipe, cocreador sino como "votante" o "público" que los agentes artísticos, en forma de políticos, necesitan recluir. Pero si algo está sucediendo ya en la segunda década del siglo XXI es que la sociedad cambia de forma rápida y continua, y que el museo como agente representativo de esa sociedad necesita crear las condiciones espaciales que reflejen ese cambio. Las propuestas expositivas de las grandes exposiciones internacionales pueden dar unas pautas hacia esta dirección.

Las últimas propuestas de documenta y especialmente de la I4 se entienden como síntomas de desarrollos culturales y cambios políticos y sociales inter nacionales más generalizados. Desde el principio, documenta persigue una concepción opuesta a la del Cubo Blanco, aquel espacio perfecto e impoluto en el que Brian O'Doherty coloca a su espectador para estudiarlo. Un espacio en el que, según el crítico de arte irlandés, si bien la mirada es bienvenida, el cuerpo no lo es, entendido como interferencia que molesta el discurso. Un espacio muy exitoso durante todo el siglo $\mathrm{xx}$, pero que actualmente se está demostrando inadecuado para acoger sensibilidades múltiples y diversas. Como museo temporal, documenta experimenta con nuevos conceptos de exhibición y establece importantes bases para la comprensión institucional del arte, interesándose, desde mi punto de vista, en temas centrales del sistema de arte para así poder representar mediante sus propuestas una sociedad cambiante.

El caso de D I4 es muy claro: quiere crear las posibilidades y las circunstancias para el surgimiento de una sociedad nueva al intentar establecer relaciones nuevas que se alejan de aquellas existentes entre verdad y poder decimonónicas. Szymczyk aprovecha la oportunidad y propone el arte y su exposición como excelentes medios para reflexionar sobre el tipo de nuevos vínculos que pueden surgir entre verdad y poder a la vez que sobre el papel que puede jugar la producción artística dentro del aparentemente bien afilado sistema de producción y consumo del aparato occidental. Esta edición reflexiona, entre otras cosas, precisamente sobre aquella relación con el "público". Le interesa mucho el conocimiento que el espectador puede aportar. Un conocimiento que puede considerarse como instrumento para el entendimiento entre factores. En 
vez de aniñar a su visitante, esta última edición de la exposición espera crear espectadores copropietarios del resultado final, que a cada uno le pertenezca un trozo del intento. Convertirnos en propietarios en vez de consumidores de una exposición y, a través de ella, de nuestras propias vidas no es tarea fácil: "mientras no establezcamos, no materialicemos y no aprovechemos más las posibilidades de reivindicación de nuestro espacio dentro de lo común, a través del acto de una subjetivación radical, no podremos escapar de los mecanismos del poder". ${ }^{28}$

$\mathrm{El}$ arte y la forma de mostrarlo pueden producir nuevos espacios y maneras de habitarlos. Espacios comunes, abiertos y libres donde el diálogo nace, crece y se irradia más allá de lo ya hecho, visto y dicho. La manera de exponer el arte puede servir para la creación de espacios desde los que el "otro", que somos nosotros mismos, puede actuar frente a una política universal que nos mantiene rehenes. En D I4 esto queda claro: "El mundo antiguo es un mundo de pertenencia, de identidad y localización mientras que el mundo que D I4 quiere establecer es un mundo nuevo de subjetividades radicales". ${ }^{29}$

Es momento de pensar en grande y no en pequeño. Compartimos un espacio físico y un tiempo geológico muy concretos, creemos pues a partir de estos elementos, un espacio ampliado hacia lo cultural y lo histórico, más allá de nuestro tiempo personal y compartámoslo. Tenemos como únicas armas la ética y la estética, pero seguro que con su ayuda, se puede lograr.

\section{Conclusiones}

El relato central que surge de los ejemplos investigados en este texto presenta una clara problemática: la activación de la audiencia en el arte, mediante proyectos participativos que ya hace mucho tiempo que se presentan, no ha encontrado hasta hoy día el equivalente interés por parte de las instituciones museísticas, en crear espacios participativos donde desarrollarse una espectaduría activa. El deseo de activar la audiencia por medio de la participación es ese deseo, según Bishop de "emanciparla de un estado de alienación inducido por el orden ideológico dominante”, pero ¿existe realmente este deseo por parte de las instituciones?

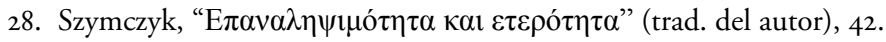

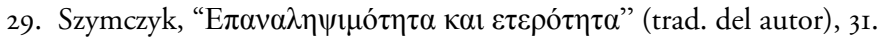


La investigación hasta ahora realizada tanto como el análisis aquí presentado proporcionan unas primeras pistas sobre la problemática del uso del espacio expositivo como medio básico de expresión estética y creación de relaciones sociales, ambas requisitos necesarios en la ardua tarea de representación del cambio de la sociedad del siglo xxI.

La colaboración de disciplinas como la historia, antropología social, geografía o historia del arte por parte del llamado "complejo expositivo", ha dado como resultado la creación del museo como un espacio representacional lineal e historicista, el cual ha permitido hasta ahora la creación de una especie de ordenamiento de cosas y personas estrictamente estructurado en línea cronológica y excluyente, apartada de los flujos habituales en la vida cotidiana.

Se ha investigado las relaciones entre el arte participativo del siglo $\mathrm{xx}$ y unas prácticas expositivas de documenta en su última edición número I4, y se ha introducido la idea de un espacio expositivo distinto del tradicional de las tres dimensiones y ampliado hacia lo temporal y lo social, creando un nuevo espacio polidimensional en el que la exposición artística se desarrolla como una nueva práctica artística autónoma y socialmente comprometida.

El presente artículo no intenta presentar D I4 como un extraordinario cambio del paradigma en las políticas expositivas institucionales. Es cierto que se trata de una tendencia de la última década, casi consolidada, no obstante la presentación de D I4 en dos sedes por igual en relación con la coyuntura político-social internacional, hace que dicho paradigma funcione como perfecto ejemplo para los estudios de la construcción social del espacio expositivo.

Conocida por muchos como "la exposición de arte actual más grande del mundo", documenta, en su última edición, traslada su sede fija de la ciudad de Kassel y se establece por primera vez por igual en otra ciudad, a saber, la capital de la crisis económica actual, Atenas. Como herramienta principal ese traslado y esa coexistencia, su director artístico, Adam Szymczyk, reflexiona acerca de las posibilidades del uso del arte como medio de unir en vez de separar. Unir espacios y sensibilidades distintas y a veces opuestas desde el respeto y el reconocimiento de la necesidad de creación de una realidad distinta a la impuesta por parte de ciertos centros de poder.

Unir no puede ser sinónimo de unificar u homogeneizar. Entiendo unir como abrir, ampliar y expandir. Expandir nuestro espacio y expandirnos hacia el prójimo con un deseo claro: conocerle y enriquecernos de él, ofrecerle nuestras ideas y aprender de las suyas. No "tolerarle" sino crear juntos un espa- 
cio ampliado y expandible hacia una sociedad participativa para así facilitar el surgimiento de una esfera pública en la que se valore la visibilidad del otro.

Hoy día, transcurriendo ya la segunda década del siglo xxI, resulta pertinente definir el lugar del espectador en el espacio de la exposición y por medio de ello, su lugar en la sociedad. Poner en cuestión el orden social establecido, mediante prácticas artísticas, no debería dar miedo, al fin y al cabo, evita que la democracia desaparezca. Ni olvidemos que tanto arte como democracia son procesos en continua evolución. En esta búsqueda, el arte del siglo XXI y el museo tienen que explorar juntos las posibilidades y sentar las bases de un espacio cultural común que refleje las experiencias compartidas de la heterogeneidad reconociendo que la filosofía, el arte y la vida están más profundamente entrelazadas de lo que hasta ahora, admitían las convenciones del museo.

Si la función esencial del museo del siglo XxI es ser instrumento de desarrollo social y cultural al servicio de una sociedad democrática, a la vez que fomentar el crecimiento y el progreso de una ciudadanía cada vez más exigente y participativa, entonces escuchar la filosofía y el arte y tener la mano tendida a propuestas expositivas distintas, debería ser parte fundamental en el desarrollo y la evolución del museo actual.

En la hipotética pregunta: ¿Qué hay de nuevo en los museos después de tanto tiempo de exponer arte? una hipotética respuesta podría ser: la voluntad de parte de la institución y sus agentes, de crear con la ayuda del arte, un espacio representativo para el conjunto de la sociedad. $\$$ 